\title{
UNA REINTERPRETACION DE LAS CRISIS ECONOMICAS MUNDIALES \\ DE 1929 Y DE 1973. \\ UN ANALISIS DEL SECTOR TRIGUERO *
}

\author{
JUAN HERNANDEZ ANDREU \\ Universidad Complutense de Madrid
}

En este artículo pretendo reflexionar sobre los orígenes de las dos crisis económicas mundiales más importantes del siglo xx: la de 1929 y la de 1973. Recientemente, Pedro Fraile y yo presentamos un ensayo en el IX Congreso Mundial de Historia Económica en el que tratamos de fundamentar, teórica y empíricamente, la causalidad de la Relación de Intercambio (RI) de los bienes primarios respecto a las manufacturas en los inicios de ambas crisis ${ }^{1}$.

La observación empírica muestra (véanse gráficos I y II) que los precios de los alimentos y materias primas, en relación a los precios de los productos industriales, descendieron, en un plano mundial, antes de la crisis de 1929; a su vez, observamos que la RI de los productos del sector primario respecto a las manufacturas, con un enfoque mundial también, era declinante antes de 1972-1973 y desde el término de la guerra de Corea. Después de la crisis mejorarán, en ambos casos, las RI de los bienes primarios; en el caso de los alimentos y materias primas, los cambios al alza serán en 1933 y en 1972, respectivamente; para el petróleo (no dispongo de datos de la RI del petróleo respecto a las manufacturas con anterioridad a la II Guerra Mundial) el incremento se registra en 1973. Como contrapunto, si abandonamos el enfoque sectorial y atendemos a Inglaterra, observamos que la RI de este país comenzará a decaer, desde 1933 en la primera crisis y desde 1972 en la segunda.

En el trabajo antes mencionado, en base a un modelo interpretativo que establece a la producción industrial mundial como variable dependiente y a la RI de los productos primarios y al comercio mundial de los alimentos, materias primas y fuel como variables independientes, hallamos una base eco-

* Agradezco a Gabriel Tortella, Pedro Fraile y a dos lectores anónimos la lectura de un primer borrador de este ensayo, cuyas importantes sugerencias fueron para mí de gran utilidad.

' Kindleberger (1973); Temin (1976); Rostow (1983); Malenbaum (1953); Timoshenko (1953); Farnsworth (1945); Hilgerdt (1945); Hernández Andreu (1980); Latham y Larry Neal (1983); Pedro Fraile y Hernández Andreu (1986); Díaz Alejandro (1985); Platt y Di Tella (1985). 


\section{GRAFICO I}

Relación de intercambio: indice de precios de bienes primarios/ indice de precios de manufacturas, 1880-1930

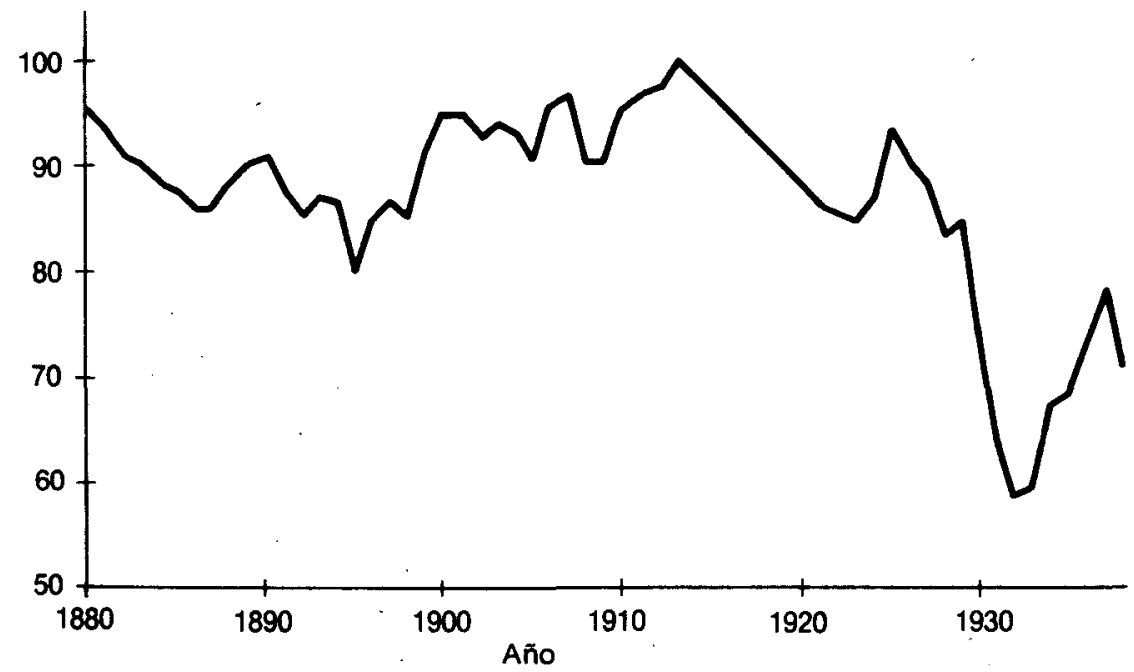

FuenTE: Pedro Fraile y Juan Hernández Andreu (1986).

\section{GRAFICO II}

Relación de intercambio: indice de precios de bienes primarios/ indice de precios de manufacturas, 1950-1980

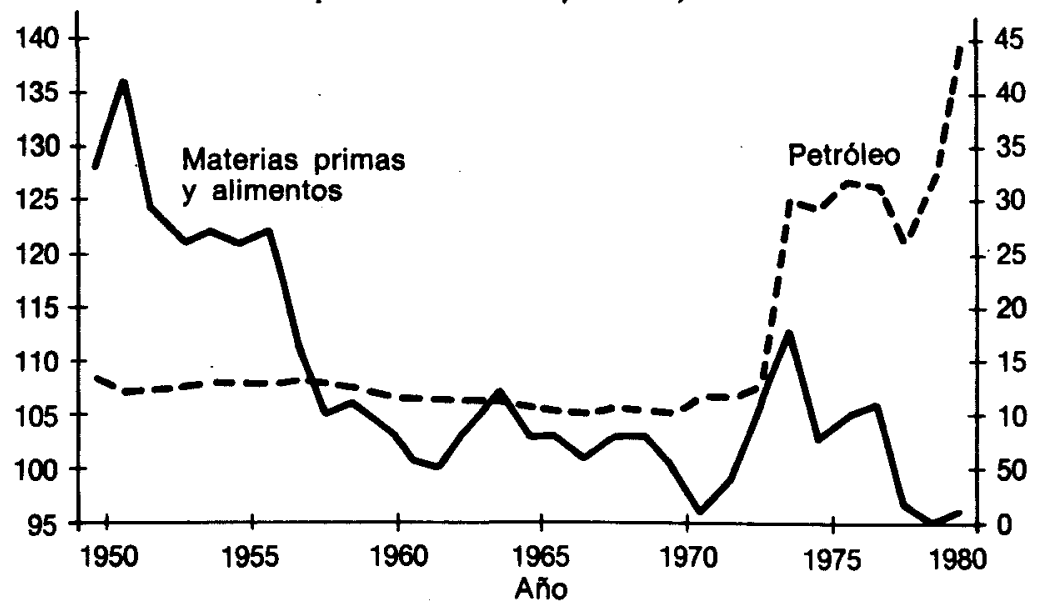

Fuente: Pedro Fraile y Juan Hernández Andreu (1986). 
nométrica para la causalidad de la RI de los bienes primarios respecto a las manufacturas en los orígenes de las dos grandes crisis económicas.

Observamos que la industrialización crece cuando la RI de los productos del sector primario es desfavorable respecto a los bienes industriales; asimismo, consideramos que las crisis económicas vienen precedidas de un auge industrializador acompañado de una RI declinante para los bienes primarios, tendencia que cambia de signo en 1933 y en 1972-1973, respectivamente, registrándose un alza en la $\mathrm{RI}$ de las materias primas, alimentos y petróleo.

Entendemos que este planteamiento encaja con la tesis fundada en el concepto de «deflación estructural», consistente en que un cambio en los precios relativos de las mercancías del sector primario respecto al secundario ocasiona un proceso depresivo en la economía del mundo a través de los mecanismos del comercio internacional, tesis expuesta por Lewis, Kindleberger y Rostow. Asimismo, Temin define la depresión estructural como un proceso por el que un cambio en unos precios relativos afecta a la producción de todo el sistema.

La observación empírica de los hechos, la contrastación econométrica en mi trabajo en colaboración con Pedro Fraile, así como la tesis Lewis-Kindleberger-Rostow, evidencian un papel sustancial de la RI de los bienes primarios respecto a las manufacturas en los orígenes de las dos grandes crisis; sin embargo, los mecanismos generadores de éstas requieren algunas precisiones.

Asi tenemos que en el comienzo de la crisis de 1929 se registra un aumento de stocks de los bienes primarios y una caída de sus precios, lo cual, siguiendo a Kindleberger, dio lugar a una descenso de rentas en los países exportadores de materias primas y de alimentos; $y$, si tenemos en cuenta que 2/3 del comercio internacional era de productos primarios, ello generó un descenso en la demanda de productos industriales. No olvidemos que los sectores del crecimiento industrial de la segunda mitad del decenio de 1920 son sectores de una gran elasticidad renta-demanda (vivienda, automóviles, electrodomésticos), según estudió Rostow para Estados Unidos. En cambio, el origen de la crisis industrial de 1972-1973 proviene del encarecimiento en la producción de bienes industriales al cambiar de signo la RI de bienes primarios respecto a manufacturas, al menos en el caso del fuel el fenómeno es evidente; al aumentar el precio del petróleo se incrementaron los costes de las producciones industriales, lo cual condujo a un estancamiento industrial con inflación.

La diferenciación que acabo de exponer no excluye que antes de ambas crisis actúe una RI desfavorable para los bienes primarios y que exista una depresión estructural en este sector, que acompaña a la industrialización de 1925-1929 y a la de 1953-1972; no obstante, el cambio de tendencia, es decir, el declive en la producción industrial, en el primer caso proviene del lado 
de la demanda y en el segundo del lado de la oferta; asimismo, ello también explica que el resultado en la marcha de los precios sea distinto en ambos períodos; en el primero desciende el índice internacional de precios, resultado de la caída de precios de los bienes primarios que se transfiere al conjunto de la economía; en el segundo, la escasez de bienes primarios o los controles de oferta de los mismos, como en el caso del fuel, forzaron el cambio de tendencia de precios relativos de estos bienes hacia una notable alza que repercutió en el aumento general de precios, pero en un contexto de depresión estructural que alcanzó a la industria, dando lugar a la llamada estanflación en 1974-1975.

En otros lugares he presentado las distintas teorías y explicaciones histórico-económicas existentes que tratan de explicar los orígenes de las crisis económicas, así como los argumentos que me llevaron a resaltar las fuerzas estructurales y los mecanismos del comercio internacional para interpretar las grandes fluctuaciones económicas; pero en este trabajo sólo considero a la causalidad de los precios relativos de los bienes primarios y secundarios en las dos grandes crisis de 1929 y de 1972-1973; partiendo de la tesis general que expuse antes, analizaré más en concreto las tendencias de los stocks y precios del trigo en los países exportadores de este cereal, y en Inglaterra como importador, antes y después de la crisis de 1929; asimismo, veré la marcha de los stocks y precios mundiales de dicho cereal antes y después de la crisis de 1972-1973. Además, atenderé a la evolución de los indicadores económicos en los países elegidos.

Mi estudio se centra en el análisis histórico-económico de Estados Unidos, Australia, Argentina, Canadá y Reino Unido desde el término de la Primera Guerra Mundial hasta nuestros días, y en el trigo que, a su vez, vincula a los cinco países seleccionados, a los cuatro primeros como principales exportadores de este bien y al último como importador.

Además, apoya la muestra elegida el hecho de que Estados Unidos e Inglaterra fueron los países que se disputaron el liderazgo de la economía mundial entre las dos grandes guerras; posición que el primero ha alcanzado indiscutiblemente desde 1945. El Reino Unido sigue siendo una de las primeras potencias económicas del mundo, y su presencia como consumidor de bienes del sector primario y de vendedor de bienes industriales en los mercados internacionales es de primer orden. Los tres países restantes tienen en común su condición de principales exportadores de trigo, si bien los derroteros de Argentina han sido distintos a los de Canadá y Australia.

Para realizar este estudio he elaborado series de las variables de producción, superficie sembrada, importaciones y exportaciones de trigo de los cinco países señalados entre 1921 y 1980 , pero que, por razones de espacio, aquí no transcribo; asimismo, del Producto Nacional Bruto (PNB), Población e 
Inversión/PNB, de todos ellos para el mismo período. También utilizo las variables Precios, Relación de Intercambio (RI) y otras específicas que referiré luego ${ }^{2}$.

Mi hipótesis-conclusión básica es que, tanto la crisis económica de 1929 como la de 1972-1973, obedecen primordialmente a desequilibrios estructurales y son susceptibles de ser explicadas con analogía.

\section{Canadá}

La expansión triguera canadiense entre 1901 y 1905 estuvo acompañada de afluencia de capital, que se destinó a la construcción de ferrocarriles; el crecimiento económico anterior a 1914 se funda en el trigo. La guerra acentuó la dependencia de la economía canadiense de sus exportaciones de productos del sector primario ${ }^{3}$.

A partir de 1925 aumenta la producción triguera, crecen los stocks y cae el precio del trigo, proceso que se intensifica a partir de 1929 , iniciándose la recuperación en 1933-1934; el alza productiva se cortaría en 1934 y de los stocks en 1937-1938 (véase cuadro 1); la caída de las exportaciones se inicia en 1929, de modo drástico, y luego sigue con fluctuaciones y tendencia decli-

\section{CUADRO 1}

\section{"Stocks» y precios del trigo en Canadá}

\begin{tabular}{|c|c|c|c|c|c|}
\hline Años & (1) & (2) & $A \tilde{n} o s$ & (1) & (2) \\
\hline $\begin{array}{lllll}1921-22 & \ldots & \ldots & \ldots & \ldots \\
1922-23 & \ldots & \ldots & \ldots & \ldots \\
1923-24 & \ldots & \ldots & \ldots & \ldots \\
1924-25 & \ldots & \ldots & \ldots & \ldots \\
1925-26 & \ldots & \ldots & \ldots & \ldots \\
1926-27 & \ldots & \ldots & \ldots & \ldots \\
1927-28 & \ldots & \ldots & \ldots & \ldots \\
1928-29 & \ldots & \ldots & \ldots & \ldots \\
1929-30 & \ldots & \ldots & \ldots & \ldots\end{array}$ & $\begin{array}{r}0,24 \\
1,56 \\
0,48 \\
2,96 \\
3,03 \\
3,66 \\
4,84 \\
13,61 \\
22,91\end{array}$ & $\begin{array}{l}\overline{111,4} \\
104,3 \\
168,1 \\
151 \\
146,1 \\
146,3 \\
123,9 \\
124,2\end{array}$ & $\begin{array}{lllll}1930-31 & \ldots & \ldots & \ldots & \ldots \\
1931-32 & \ldots & \ldots & \ldots & \ldots \\
1932-33 & \ldots & \ldots & \ldots & \ldots \\
1933-34 & \ldots & \ldots & \ldots & \ldots \\
1934-35 & \ldots & \ldots & \ldots & \ldots \\
1935-36 & \ldots & \ldots & \ldots & \ldots \\
1936-37 & \ldots & \ldots & \ldots & \ldots \\
1937-38 & \ldots & \ldots & \ldots & \ldots \\
19\end{array}$ & $\begin{array}{r}16,09 \\
5,54 \\
5,89 \\
7,69 \\
9,95 \\
11,70 \\
19,27 \\
4,11\end{array}$ & $\begin{array}{r}64,3 \\
59,8 \\
54,3 \\
68,1 \\
81,8 \\
84,6 \\
122,7 \\
135,6\end{array}$ \\
\hline
\end{tabular}

(1) Total de stocks a 1 de agosto (millones de Bushels).

(2) Precios (centavos canadienses/Bushel).

FuENTE: Hevesy (1940).

\footnotetext{
2 Véase relación de fuentes cuantitativas expresadas al final de este artículo.

${ }^{3}$ Kemp (1981), 175 y ss.; Rostow (1983), 472; Safarian (1959), 101.
} 
nante. La relación de intercambio decrece desde 1926. El PNB desciende entre 1930 y 1931, y el desempleo llega al 20,6 por 100 en 1934; asimismo, la inversión de capital sobre el PNB desciende entre 1929 y 1936.

El crecimiento canadiense, después de la Segunda Guerra Mundial, contó con la ayuda financiera de capital extranjero. El porcentaje de mano de obra en el sector terciario pasó de un 33,7 por 100 en 1931 a un 50 por 100 en 1961; en el mismo período, el porcentaje de la manufactura, la construcción y el transporte aumentó del 33,8 por 100 al 36 por 100 , y el empleo en el sector primario descendió del 32,6 al 13,5; no obstante, las exportaciones canadienses son de productos primarios, fundamentalmente; y Canadá depende de capital extranjero para su crecimiento 4.

Se observa que en el decenio de 1960 aumentaron las exportaciones de trigo, sin que este fenómeno fuera acompañado de un aumento sustancial en la producción; en 1970, 1971 y 1972 las exportaciones trigueras tuvieron que basarse en la liquidación de stocks.

La relación de intercambio de Canadá creció entre 1973 y 1977 (véase cuadro 2) a raíz del aumento del precio mundial del trigo; asimismo, la ratio

CUADRO 2

Relación de intercambio $(1970=100)$

\begin{tabular}{|c|c|c|c|c|c|}
\hline Años & Argentina & Australia & Canadá & R. Unido & EE. UU. \\
\hline 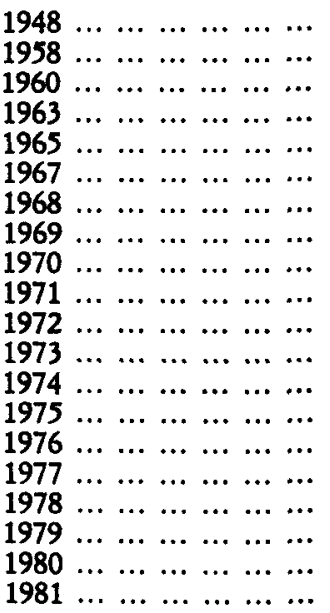 & $\begin{array}{r}128 \\
110 \\
108 \\
107 \\
109 \\
105 \\
101 \\
102 \\
100 \\
94 \\
93 \\
114 \\
116 \\
105 \\
105 \\
98 \\
97 \\
100 \\
96 \\
-\end{array}$ & $\begin{array}{r}- \\
\overline{100} \\
98 \\
103 \\
98 \\
96 \\
97 \\
100 \\
106 \\
106 \\
120 \\
103 \\
87 \\
78 \\
72 \\
67 \\
- \\
-\end{array}$ & $\begin{array}{r}94 \\
96 \\
98 \\
92 \\
95 \\
99 \\
99 \\
99 \\
100 \\
99 \\
100 \\
106 \\
114 \\
109 \\
112 \\
106 \\
101 \\
106 \\
107 \\
103\end{array}$ & $\begin{array}{r}91 \\
94 \\
96 \\
98 \\
99 \\
102 \\
98 \\
98 \\
100 \\
101 \\
95 \\
93 \\
80 \\
86 \\
84 \\
86 \\
92 \\
93 \\
91 \\
\end{array}$ & $\begin{array}{r}103 \\
94 \\
96 \\
99 \\
98 \\
101 \\
101 \\
102 \\
100 \\
98 \\
95 \\
93 \\
77 \\
80 \\
82 \\
77 \\
77 \\
73 \\
66 \\
69\end{array}$ \\
\hline
\end{tabular}

FuENTES: United Nations, Statistical Yearbook; United Nations (1981).

4 Lithwick (1967). 
de paridad entre «precios recibidos» y «precios pagados» por los agricultores muestra una mejora relativa de éstos desde 1972 y hasta 1976. Sin embargo, dada la estructura industrial interna, el PNB canadiense experimentó un estancamiento en 1975; fenómeno análogo se observa en la inversión de capital respecto al PNB; el porcentaje de paro comenzó a subir en 1976. En Canadá, la mejora relativa de precio del trigo no pudo compensar completamente las consecuencias del aumento de precio del petróleo.

\section{Australia}

A fines del siglo pasado se pusieron las bases para el crecimiento australiano, anterior a la guerra mundial, en base a exportaciones de trigo, carne y mantequilla ${ }^{5}$. La crisis económica de 1929 sobrevino a Australia por dos factores: 1) la caída de precios de los productos de exportación, por tanto, del sector primario, y 2) por la dependencia del capital exterior, con un volumen creciente de deuda ${ }^{6}$.

De 1923 a 1928, la deuda externa australiana creció desde 420 millones de libras a 570 millones, con una media de incremento anual de 30 millones de libras. La combinación de exportaciones reducidas y la imposibilidad de obtener préstamos condujo a pérdidas de reservas y a la devaluación del cambio, transmitiendo a otros sectores el peso del ajuste. Este proceso se dio no sólo en Australia, sino también en Argentina, y en dos países muy vinculados a ellos, Uruguay y Nueva Zelanda.

Los países exportadores de trigo perdieron oro antes que otros exportadores; es el caso de Australia y Argentina. En Canadá, el fenómeno estuvo afectado por las complejas relaciones financieras de este país con Estados Unidos; no obstante, se registran pérdidas de oro en 1928 y 1929, antes del crack de la Bolsa de valores. En Hungría también se registran pérdidas de oro. Algo parecido tuvo lugar en la redistribución de reservas de oro dentro de Estados Unidos, de unos Estados respecto a otros; Nueva York ganó oro, pero lo perdieron Dallas, Sant Louis y Minneapolis ?

${ }^{3}$ Rostow (1983), 483.

- Copland (1941), 87 y ss.; Kindleberger (1973), 97-101.

- Para comprender mejor los efectos deflacionistas en y desde las economías exportadoras de bienes alimenticios y de materias primas sobre las relaciones económicas internacionales, hagamos algunas reflexiones teóricas. La Teoría económica sugiere que la depreciación del cambio valutario crea un alza de los precios de las exportaciones en moneda interna, o un descenso de los precios de las exportaciones en moneda exterior; lo que suceda depende de las elasticidades correspondientes. Para un país pequeño que no influye en los precios mundiales, de manera que la demanda de sus productos es infinitamente elástica al movimiento de los precios, el impacto total se hará notar en aumento de precios, expresados en moneda interna; para los países grandes exportadores de un bien de 
Podemos decir que primero fue la deflación, a la que siguió la depreciación monetaria argentina; ello supuso una mayor deflación económica general; luego siguió la depreciación australiana, seguida de un aumento de deflación internacional, con carácter generalizado.

El comportamiento del sector triguero en Australia señala un alza en la producción desde la Primera Guerra Mundial, que se fue acentuando desde 1930-1931; análogamente, se observa este crecimiento en la superficie sembrada; las exportaciones netas crecieron mucho entre 1930-1931 y 1932-1933, decreciendo luego y manteniéndose estables hasta 1938-1939.

También se observa, desde 1930-1931, un notable aumento del porcentaje de las exportaciones australianas de trigo sobre el total del mundo; asimismo, el precio del trigo decae desde 1925-1926 y hasta 1934-1935 (véase cuadro 3). Copland señala el descenso de la RI de Australia antes de la crisis.

En el período 1930-1940 se observa una caída de la inversión total de capitales respecto al decenio anterior; entre 1930 y 1933 declinó el PNB, recuperándose después ligeramente. Australia, para mantener, incluso aumentar, sus exportaciones trigueras, tuvo que bajar el precio del trigo, fenómeno que

\section{CUADRO 3}

«Stocks» $y$ precios del trigo en Australia

\begin{tabular}{|c|c|c|c|c|c|}
\hline Años & (1) & (2) & Años & (1) & (2) \\
\hline $\begin{array}{lllll}1922-23 & \ldots & \ldots & \ldots & \ldots \\
1923-24 & \ldots & \ldots & \ldots & \ldots \\
1924-25 & \ldots & \ldots & \ldots & \ldots \\
1925-26 & \ldots & \ldots & \ldots & \ldots \\
1926-27 & \ldots & \ldots & \ldots & \ldots \\
1927-28 & \ldots & \ldots & \ldots & \ldots \\
1928-29 & \ldots & \ldots & \ldots & \ldots \\
1929-30 & \ldots & \ldots & \ldots & \ldots \\
1930-31 & \ldots & \ldots & \ldots & \ldots\end{array}$ & $\begin{array}{l}24 \\
33 \\
34 \\
28 \\
24 \\
35 \\
36 \\
41 \\
49\end{array}$ & $\begin{array}{l}5 / 4 \\
4 / 81 / 2 \\
6 / 31 / 2 \\
6 / 11 / 2 \\
5 / 73 / 4 \\
5 / 51 / 4 \\
4 / 8 \\
4 / 7 \\
2 / 7\end{array}$ & $\begin{array}{lllll}1931-32 & \ldots & \ldots & \ldots & \ldots \\
1932-33 & \ldots & \ldots & \ldots & \ldots \\
1933-34 & \ldots & \ldots & \ldots & \ldots \\
1934-35 & \ldots & \ldots & \ldots & \ldots \\
1935-36 & \ldots & \ldots & \ldots & \ldots \\
1936-37 & \ldots & \ldots & \ldots & \ldots \\
1937-38 & \ldots & \ldots & \ldots & \ldots \\
1938-39 & \ldots & \ldots & \ldots & \ldots \\
\end{array}$ & $\begin{array}{l}60 \\
50 \\
55 \\
85 \\
57 \\
43 \\
41 \\
50\end{array}$ & $\begin{array}{l}2 / 101 / 2 \\
2 / 111 / 2 \\
2 / 73 / 4 \\
2 / 111 / 4 \\
3 / 71 / 2 \\
5 / 01 / 2 \\
5 / 1 \\
-\end{array}$ \\
\hline
\end{tabular}

(1) Stocks a 1 de agosto (millones de Bushels).

(2) Precios (Shillings/Bushel).

Fuente: Hevesy (1940).

demanda inelástica, caerán los precios extranjeros. Según Marcus, la depreciación monetaria en Argentina y Australia causó la caída de los precios del trigo; sin embargo, Copland indica que el descenso de los precios resultó de la deflación internacional; los precios oro fueron deflacionados independientemente de las depreciaciones monetarias. Kindleberger (1973), 102 y ss. 
fue general, y devaluar la moneda, como vimos antes, lo cual tuvo un efecto deflacionista, según se registra en la caída del PNB, y crece el desempleo ${ }^{8}$.

La Primera Guerra Mundial tuvo escasa influencia industrializadora para Australia, pero no así la Segunda. Sin embargo, entre 1948 y 1968, el porcentaje de trabajadores industriales y el valor de la producción industrial cayeron en todas las ramas, salvo en metalurgia, maquinaria, vehículos y productos químicos 9 . Australia incorporó la tecnología industrial moderna mediante la importación de capitales que financiaba a través de las exportaciones del sector primario. Entre 1965 y 1970 , el 71 por 100 de las exportaciones australianas lo constituían la lana, el trigo, la carne, otros productos agropecuarios y los minerales. No obstante, después de la Segunda Guerra Mundial, Australia experimentó una industrialización, pero a costa, como Canadá, de una dependencia de capital exterior.

Es ilustrativo el análisis de la depresión australiana de la década de 1970. La producción australiana de trigo venía creciendo desde 1960; asimismo, se registra una tendencia creciente en las exportaciones, pero la relación de intercambio de Australia era baja respecto a 1948 y 1960, hasta que mejoró entre 1973 y 1975 , debido al alza de precio del trigo. La situación favorable a los exportadores de trigo se debilita de nuevo en los últimos años del decenio; por otra parte, la mejora de renta para los agricultores, expresada en la ratio de paridad entre «precios recibidos» y «precios pagados», sólo se observa para los años 1972 y 1973. También se registra que el alza de las exportaciones trigueras entre 1970-1971 y $1972-1973$ se hizo disminuyendo los stocks; durante los restantes años del decenio crecen paralelamente la producción y las exportaciones. Sin embargo, atendiendo a la economía en su conjunto, se observa un crecimiento ininterrumpido del volumen de desempleo desde 1972; asimismo, el PNB entra en un estancamiento. Un estudio sobre el declive económico australiano del decenio de 1970 señala que los efectos de la relación de intercambio sólo fueron positivos para el PNB entre 1970-1971 y 1973-1974, y negativos para el conjunto del decenio; asimismo, se demuestra que el declive en la tasa de crecimiento del PNB obedece al descenso en la productividad y de la producción industrial; esta última disminuyó en términos absolutos y de modo notable en 19741975, y la tasa de productividad comenzó a descender desde entonces ${ }^{10}$.

- Copland (1941), 85; Kindleberger (1973), 104-105. El porcentaje de PNB dedicado a la inversión fue grande en Australia, análogamente a Canadá, desde 1861 y en base a la importación de capital.

Rostow (1983), 489.

${ }^{10}$ Norton y McDonald (1983), 1-29. Además, se señala la correlación existente, en términos cuantitativos y desde 1973, de un gran crecimiento en precios de consumo, oferta monetaria, gastos del Gobierno y salarios; por otro lado, desciende la tasa de beneficio a partir de entonces. Está claro que el incremento de la oferta monetaria no ocasionó la recuperación económica, más bien impulsó la crisis en términos reales. 


\section{Argentina}

La economía argentina, especializada desde el decenio de 1820 en la producción y exportaciones de productos agropecuarios, experimentó cambios importantes desde comienzos de 1880 hasta la víspera de la Primera Guerra Mundial, con los ferrocarriles, con los nuevos cultivos de trigo y maíz y con los buques refrigerados. Después del crecimiento de principios de siglo hubo un retroceso económico, y durante la década de 1920 tuvo lugar cierta recuperación. Con posterioridad al declive de principios del decenio de 1930, la economía argentina creció bastante rápidamente, sobre todo durante la Segunda Guerra Mundial. Desde 1945-1949, Argentina experimentó un incremento anual de sólo 1,2 por 100 del PNB por individuo; en cambio, Australia y Canadá doblaron esta tasa de crecimiento; la economía argentina declinó profundamente ".

Veamos, en primer lugar, las características del período 1925-1932. En 1930, la expansión de la demanda mundial de productos agropecuarios y las explotaciones de nuevas tierras en la «pampa» dejaron de ser factores impulsores del crecimiento económico argentino. La caída del comercio internacional que siguió a la crisis de 1929 redujo las exportaciones argentinas de productos del sector primario.

A partir de 1925.1926 aumentaron la producción y los stocks de trigo en Argentina hasta 1929-1930. Los precios cayeron desde 1925-1926 hasta 1933-1934 (véase cuadro 4). Las exportaciones trigueras, que tuvieron una marcha fluctuante durante la década de 1920 , descienden durante los primeros años del decenio siguiente. El PNB decae entre 1929 y 1934.

Los factores críticos para la economía argentina fueron, por un lado, el empeoramiento de la RI, entre 1925 y 1932 , y, por otro, que aumentaron los costes del servicio de capital extranjero.

A comienzos del decenio de 1930 se inició una política de sustitución de importaciones, fundada en el entendimiento entre los industriales y los terratenientes argentinos, y dirigida a apoyar las industrias ya existentes. A comienzos de 1940 el producto bruto industrial supera el producto agropecuario por primera vez en la historia del país. La tasa de crecimiento argentino fue superior a la de Canadá y Estados Unidos durante la década de 1930; no obstante, Argentina agotó su ciclo en el proceso de sustitución de importaciones en 1950, que coincide con el desplazamiento de Inglaterra por Estados Unidos como su primer acreedor.

Entre 1950 y 1960 , el crecimiento económico argentino es lento, a pesar de la absorción de tecnologías modernas ${ }^{12}$. La persistencia de limitaciones

1 Rostow (1983), 493.

12 Rostow (1983), 496. En 1953 comenzaron a aumentar los salarios reales y a caer los 


\section{CUADRO 4}

\section{"Stocks» y precios del trigo en Argentina}

\begin{tabular}{|c|c|c|c|c|c|}
\hline$A \tilde{n} o s$ & (1) & (2) & $A \tilde{n} o s$ & (1) & (2) \\
\hline $\begin{array}{lllll}1922-23 & \ldots & \ldots & \ldots & \ldots \\
1923-24 & \ldots & \ldots & \ldots & \ldots \\
1924-25 & \ldots & \ldots & \ldots & \ldots \\
1925-26 & \ldots & \ldots & \ldots & \ldots \\
1926-27 & \ldots & \ldots & \ldots & \ldots \\
1927-28 & \ldots & \ldots & \ldots & \ldots \\
1928-29 & \ldots & \ldots & \ldots & \ldots \\
1929.30 & \ldots & \ldots & \ldots & \ldots \\
1930-31 & \ldots & \ldots & \ldots & \ldots\end{array}$ & $\begin{array}{r}61 \\
64 \\
66 \\
58 \\
67 \\
69 \\
95 \\
130 \\
65\end{array}$ & $\begin{array}{r}10,99 \\
11,27 \\
14,08 \\
13,15 \\
11,73 \\
11,16 \\
9,41 \\
9,90 \\
6,12\end{array}$ & $\begin{array}{lllll}1931-32 & \ldots & \ldots & \ldots & \ldots \\
1932-33 & \ldots & \ldots & \ldots & \ldots \\
1933-34 & \ldots & \ldots & \ldots & \ldots \\
1934-35 & \ldots & \ldots & \ldots & \ldots \\
1935-36 & \ldots & \ldots & \ldots & \ldots \\
1936-37 & \ldots & \ldots & \ldots & \ldots \\
1937-38 & \ldots & \ldots & \ldots & \ldots \\
1938-39 & \ldots & \ldots & \ldots & \ldots \\
\end{array}$ & $\begin{array}{r}80 \\
65 \\
75 \\
118 \\
85 \\
65 \\
51 \\
65\end{array}$ & $\begin{array}{r}6,27 \\
5,72 \\
5,64 \\
6,41 \\
9,40 \\
12,11 \\
13,27 \\
7\end{array}$ \\
\hline
\end{tabular}

(1) Total de stocks a 1 de agosto (millones de Bushels).

(2) Precios (pesos papel/quintal).

FuENTE: Hevesy (1940).

económico-estructurales condujo a la depresión de la década de 1970. Entre 1973 y 1980, la política de adquirir equipos industriales baratos, junto a una divisa revaluada artificialmente, llevó a un creciente déficit exterior. La euforia se cortó con la quiebra de algunos de los más importantes bancos argentinos, y desde entonces se aceleró la depresión económica ${ }^{13}$.

En la década de 1960 se registra una tendencia ascendente de exportaciones trigueras, con un máximo en 1965, y que se efectúa a base de liquidar stocks; en 1971 tiene lugar el volumen máximo de exportación del siglo, que implica también vender stocks; en los años siguientes, hasta 1976, las exportaciones presentan un nivel bajo, que supone un desaprovechamiento del alza de la RI motivada por el aumento de precio del trigo, registrada en 1973 y que descenderá en los años sucesivos (véase cuadro 2), acusando la respuesta de, los países industriales al aumento del precio de los productos del sector primario, con el alza del precio de los bienes manufacturados.

El PNB muestra una marcha fluctuante entre 1973 y 1978, con alzas en

precios relativos de la agricultura. La mayoría de las sustituciones de importaciones del decenio de 1950 fueron en petróleo, acero, química y vehículos a motor. Balassa (1982), 84-85.

${ }_{13}$ El crecimiento económico se hubiera mantenido moderadamente en las economlas exportadoras de no haber irrumpido, en 1980, un cambio radical en la economía internacional como fue la drástica subida de los tipos de interés y la paulatina revalorización del dólar con relación al resto de las valutas monetarias. El incremento de divisas, resultado del aumento de precio del trigo, se tradujo en alza de importaciones. Balassa (1982), 86. 
1974 y 1977, años que registraron también aumentos en las inversiones de capital respecto al PNB, lo cual supone inversiones de capitales extranjeros, además de préstamos recibidos del exterior ${ }^{14}$, situación que fue intensificándose en 1980 y $1985^{15}$.

\section{Inglaterra, Estados Unidos y la economia mundial}

En este apartado no pretendo hacer un estudio detallado de las crisis económicas de 1929 y 1973 en Inglaterra y Estados Unidos, sino señalar que la explicación de ambas crisis obedece, sobre todo, a factores estructurales.

En 1929 la crisis afectó a toda la economía inglesa, y en 1931 se registra la crisis financiera internacional; entonces, el Gobierno inglés devaluó la libra y restringió el libre cambio a los países tradicionalmente vinculados a la Corona británica, creándose la Commonwealth. El resultado fue una relativa recuperación económica, en parte producida por la demanda potencial de bienes insatisfechos durante la fase anterior de estancamiento económico, como es el caso de la construcción de viviendas; el PNB desciende en los primeros años de la década y crece el paro. Las importaciones de trigo aumentan, aunque poco, en el decenio de 1930 y crece la producción triguera interna desde 1933, al tiempo que irá empeorando su RI, así como también se recuperará el precio del trigo.

En Estados Unidos, si bien el sector agrario, análogamente a las economías de países especializados en las exportaciones de productos de este sector, padeció un descenso de precios y aumento de stocks desde antes de 1929; no obstante, hubo una expansión industrial entre 1925 y 1929; este año el declive se generalizó a todos los sectores económicos. Aparte de los efectos inducidos por la deflación estructural de las producciones agrarias, Rostow ha señalado que la estructura de las industrias que se habían expandido durante el decenio de 1920 también contribuyó a la crisis de 1920; la industria del automóvil, la química y la electricidad eran industrias caracterizadas por una gran elasticidad demanda-renta ${ }^{16}$. El crecimiento de las industrias tradicionales había sido muy limitado entre 1925 y 1929 . La ratio entre precios recibidos y precios pagados por los agricultores desciende entre 1925 y 1933, reflejo del declive del sector agrario.

El entendimiento de las tendencias económicas entre 1945 y 1980 requie-

14 Suplement Handbook of International Trade and Development Statistics (1981); CEPAL (1980), 448-449 (Deuda externa).

is United Nations (1981). Desde 1972, el aumento espectacular de los precios, el alza de la oferta monetaria, el deterioro del tipo de cambio y la perdida de valor adquisitivo de los salarios, incluso descenso en términos nominales, fueron unidos.

${ }_{16}$ Rostow (1983), 232. 
re una atención a la economía mundial. En este sentido, recordaré especialmente el ciclo 1951-1972 y la tendencia económica entre 1972 y 1980, llegando, así, al establecimiento de elementos de juicio para comprender la crisis actual y sus orígenes, contrastados con los de la crisis de 1929.

\section{$1951-1972$}

En 1933 comenzaron a crecer los precios de los alimentos y materias primas y se mantuvieron altos hasta principios del decenio de 1950, estimulados por la Segunda Guerra Mundial y la guerra de Corea ${ }^{17}$; entonces se inicia una caída de los precios de bienes primarios, al tiempo que nace un período de crecimiento en Europa.

En 1950, el comercio mundial superaba los niveles anteriores a 1929, en base al crecimiento de las relaciones comerciales ultramarinas. Después de la Segunda Guerra Mundial no hubo crisis de reconversión a una economía de paz; el proceso se hizo en un ambiente de precios relativamente elevados de alimentos y materias primas, hasta 1951. Los despegues latinoamericanos de la década de 1930 fueron acompañados de precios más altos para sus exportaciones.

Entre 1951 y 1972, la producción industrial y el comercio del mundo crecieron un 5,6 y un 7,3 por 100 , como medidas anuales, respectivamente. En Europa, el crecimiento fue posible por la emigración de mano de obra del Sur hacia el Norte, beneficiando simultáneamente las dos áreas; asimismo, las migraciones del ámbito rural a las ciudades estuvieron acompañadas de aumentos de productividad agrícola. En los países industrializados el crecimiento se basó en la expansión de los sectores líderes ${ }^{18}$.

En este período, 1951-1972, existió una tendencia económica expansiva para las economías más desarrolladas; en cambio, el empeoramiento de la re-

17 Rostow (1983), 242. Señala Kindleberger que la RI europea declinó de 100 en 1938 a 83 en 1948. Kindleberger (1968), 167. Estados Unidos había llegado al pleno empleo durante la segunda guerra mundial. La recuperación europea fue posible por la ayuda económica norteamericana del Plan Marshall, que permitió cubrir el déficit de granos, algodón, petróleo, carne y otros productos que padecía Europa después de la guerra hasta que pudo mejorar la productividad agrícola.

"El precio del fuel había crecido menos que los precios de alimentos y materias primas entre 1938 y 1953; pero su declive entre 1953 y 1963 fue también menos drástico: entre 1963 y 1969 cayó absolutamente, mientras el precio de alimentos y materias primas crecía ligeramente; en 1972, los índices de ambos tiraron al alza juntos. En comparación a los precios de bienes manufacturados, los precios de fuel crecieron un poco más entre 1938 y 1951, pero aumentaron considerablemente menos entre 1951 y 1971-1972; mientras crecían los precios de las manufacturas de exportación, los precios del fuel cayeron entre 1953 y 1969. Este fenómeno es significativo de la era expansiva, dado el consumo energético de los sectores líderes en los países más industrializados. Rostow (1983), 26. 
lación de intercambio de Latinoamérica fue muy marcada entre 1951 y 1971, pero sobre todo entre 1951 y 1958 . Efectivamente, ello se corrobora adoptando el enfoque sectorial del estudio de Pedro Fraile y mío, donde la RI de las materias primas y alimentos respecto a las manufacturas cae en picado de 1951 hasta 1971, y sobre todo entre 1951 y 1958 (véase gráfico II).

\section{La crisis de 1973}

Entre 1965 y 1971, por tanto, antes de la crisis de 1972, se observan escaseces en los mercados de ciertos bienes alimenticios y materias primas, especialmente en el de granos y en el mercado de petróleo; ello no sólo obedecía a la gran importancia de estos productos, sino también a la posición de reserva de Estados Unidos, como mayor oferente que había tenido poder para amortiguar los efectos de los precios mundiales de aquellos bienes, hasta que se llegó a extremos insostenibles.

En 1972-1973 hubo gran alza en los precios del grano, pero el conocimiento del decenio de 1960 explica que no fue un fenómeno que surgiera de pronto. Hasta entonces, Estados Unidos había llenado el vacío dejado por el descenso de las exportaciones de Asia, Europa oriental, URSS, Africa y, también, Latinoamérica, que cambió a posiciones deficitarias crecientes. Este proceso estuvo acompañado de una caída en las reservas mundiales de trigo. Se registra un aumento de la demanda efectiva de granos que no sólo obedecía al incremento poblacional; así, en los países en vías de desarrollo, el aumento de la población era de 2,5 por 100 al año y el consumo de granos de un 3,6 por 100; en los países desarrollados, la población aumentaba al 1 por 100 anual y la demanda se cifró en 1,7 por 100 , debido al crecimiento del consumo de carne de animales alimentados con cereales caros.

A principios del decenio de 1960, en Estados Unidos aumentaron los stocks de trigo y disminuyó la superficie sembrada; luego, los stocks cayeron desde 1962-1963 de modo continuo hasta 1968-1969, conteniéndose la caída en 1969-1970 y 1970-1971, cuando al año siguiente el descenso de los stocks será notable (véanse cuadros 5 y 6) y aumentará el precio, a consecuencia de malas cosechas habidas en la URSS y en Asia, evidenciándose la escasez mundial de grano que se arrastraba de años atrás.

El aumento de precio del trigo afectó negativamente la relación de intercambio de los países importadores de grano y provocaría, junto al incremento de precio del petróleo ${ }^{19}$, la crisis de 1973. El aumento de precio del trigo se frenará en 1976-1977, para volver a subir a finales de la década.

19 El aumento de precios de los granos, surgido del mercado internacional, estuvo acompañado del incremento espectacular de los precios del petróleo, resultado de la decisión de la OPEP. Estados Unidos había aumentado el consumo de petróleo, al tiempo 


\section{CUADRO 5}

Declive en los «stocks» de trigo y granos ordinarios (En miles de toneladas)

\begin{tabular}{|c|c|c|c|}
\hline Años & Mundial & $\begin{array}{c}\text { Mayores } \\
\text { exportadores * }\end{array}$ & EE. UU. \\
\hline $\begin{array}{lllllll}1960-61 & \ldots & \ldots & \ldots & \ldots & \ldots & \ldots \\
1961-62 & \ldots & \ldots & \ldots & \ldots & \ldots & \ldots \\
1962-63 & \ldots & \ldots & \ldots & \ldots & \ldots & \ldots \\
1963-64 & \ldots & \ldots & \ldots & \ldots & \ldots & \ldots \\
1964-65 & \ldots & \ldots & \ldots & \ldots & \ldots & \ldots \\
1965-66 & \ldots & \ldots & \ldots & \ldots & \ldots & \ldots \\
1966-67 & \ldots & \ldots & \ldots & \ldots & \ldots & \ldots \\
1967-68 & \ldots & \ldots & \ldots & \ldots & \ldots & \ldots \\
1968-69 & \ldots & \ldots & \ldots & \ldots & \ldots & \ldots \\
1969-70 & \ldots & \ldots & \ldots & \ldots & \ldots & \ldots \\
1970-71 & \ldots & \ldots & \ldots & \ldots & \ldots & \ldots \\
1971-72 & \ldots & \ldots & \ldots & \ldots & \ldots & \ldots \\
1972-73 & \ldots & \ldots & \ldots & \ldots & \ldots & \ldots \\
1973-74 & \ldots & \ldots & \ldots & \ldots & \ldots & \ldots \\
1974-75 & \ldots & \ldots & \ldots & \ldots & \ldots & \ldots \\
1975-76 & \ldots & \ldots & \ldots & \ldots & \ldots & \ldots\end{array}$ & $\begin{array}{r}169.106 \\
182.052 \\
155.410 \\
158.687 \\
153.820 \\
156.990 \\
121.242 \\
150.338 \\
162.336 \\
190.775 \\
167.993 \\
190.608 \\
148.796 \\
108.493 \\
110.452 \\
89.522\end{array}$ & $\begin{array}{r}127.838 \\
138.776 \\
115.912 \\
110.286 \\
108.790 \\
94.710 \\
69.875 \\
69.324 \\
84.446 \\
106.971 \\
112.745 \\
82.923 \\
94.534 \\
59.933 \\
47.435 \\
32.122\end{array}$ & $\begin{array}{r}103.683 \\
115.834 \\
101.654 \\
91.144 \\
87.586 \\
72.250 \\
53.243 \\
45.776 \\
59.097 \\
68.192 \\
68.714 \\
50.593 \\
68.516 \\
42.128 \\
27.110 \\
18.472\end{array}$ \\
\hline
\end{tabular}

* Estados Unidos, Canadá, Australia, Argentina.

FunNTE: Talbot (1972-76).

\section{CUADRO 6}

Indice de precios de las exportaciones mundiales de trigo $(1975=100)$

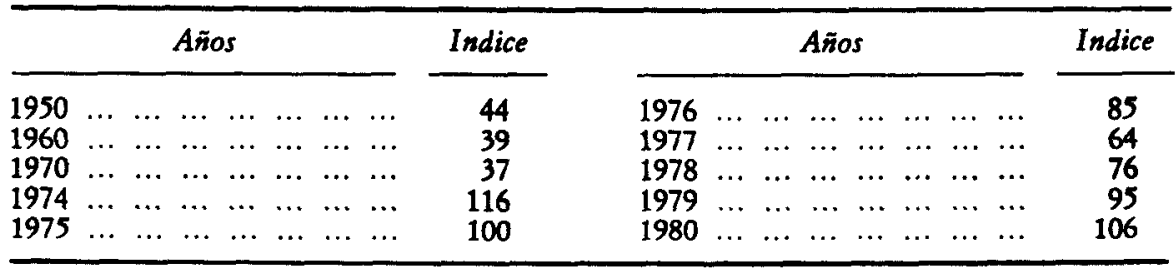

FUENTE: United Nations, Statistical Yearbook.

Desde 1973 desciende la relación de intercambio del Reino Unido con la subida de precio del trigo, de otros alimentos y de las materias primas (véase cuadro 2); desde entonces disminuyen las importaciones de trigo, al tiempo

que crecía su dependencia de las importaciones, y cuando quiso reaccionar al aumento de precios energéticos no contaba con poder regulador del precio internacional. Rostow (1983), 271-273. 
que aumenta la producción doméstica. Se observa una correlación entre caída de la RI inglesa y las importaciones netas de trigo de Inglaterra. El PNB se estanca durante la década de 1970 y crece el desempleo.

La RI de Estados Unidos decae notablemente, desde 1973, con la subida de precio del petróleo y bienes del sector primario, en general; de manera que el alza, entre 1973 y 1975 , de precio del trigo no pudo contener este descenso, dada la estructura comercial exterior norteamericana, dependiente de la importación de petróleo debido al alto consumo energético; con todo, creció la producción y las exportaciones trigueras desde 1973. En 1975 y 1976 se estanca el PNB y crece el desempleo. De 1976 a 1978 baja el precio del trigo, para volver a subir en 1979 y 1980 . Entre 1972 y 1980, después de la larga expansión postbélica. la economía mundial se estancó.

El deterioro de la relación de intercambio en Inglaterra y Estados Unidos, a partir de 1972, fue mayor que en otros países desarrollados. Los países en vías de desarrollo, en su conjunto, mejoraron su relación de intercambio respecto a la etapa anterior a la crisis, pero los no productores de petróleo la vieron notablemente empeorada.

Las naciones industrializadas sufrieron un estancamiento más inflación desconocido hasta entonces (estanflación) ${ }^{20}$; estos países sufrieron caídas o estancamiento en el PNB y acusaron aumentos en los niveles de desempleo.

A su vez, a finales de la década de 1970 se registra un nuevo incremento en los precios de los productos del sector primario, a lo que los países industrializados responderán con políticas monetarias restrictivas ${ }^{21}$, intensificándose, además, la depresión económica en los países con deuda exterior respecto a las grandes naciones industrializadas.

\section{Conclusión}

Conforme a mi concepción expuesta al principio de este ensayo, la caída de los precios de los alimentos y de las materias primas respecto a los precios

${ }^{20}$ Rostow (1983), 294 y ss. Antes de la crisis, los paises de la OCDE aumentaban su producción en un 5,2 por 100 al año y los precios crecían en un 4,1 por 100; después de 1974-1975 disminuyeron, incluso en términos absolutos, su producción y los precios aumentaron entre un 10 y un 12 por 100 . La intensidad de la revaluación de los precios obedeció a dos motivos sustanciales: 1) el incremento en la demanda de materias primas, combustibles y alimentos era vulnerable a las malas cosechas de 1972-1973 y a las medidas de la OPEP, y 2) el hecho de que a una determinada tasa de inflación correspondía un nivel de desempleo más alto. El aumento de los salarios monetarios siguió a las alzas en la tasa de inflación.

"Reino Unido y Japón han contenido sus gastos públicos. La política de Reagan, sin embargo, fue expansionista en el gasto estatal norteamericano, pero restrictiva en el terreno monetario. 
de las manufacturas antes de la crisis de 1929 y en un plano mundial fue una realidad. A su vez, observo el mismo fenómeno con anterioridad a 1972 1973 y desde el término de la guerra de Corea. Al filo de las crisis mejoraron, en ambos casos, las RI de los bienes primarios. Como contrapartida, la RI de Inglaterra comenzó a decaer, desde 1933 en la primera crisis y desde 1972 en la segunda. Esta tesis concuerda con los movimientos de stocks y precios del trigo en un plano mundial y en los países exportadores que he examinado.

En 1972.1973 hay escasez de bienes primarios y presión de la demanda, que aprovechan los productores para aumentar los precios de dichos bienes, llevando la crisis, por el lado de la oferta, a los países industrializados importadores de alimentos, materias primas y fuel, y a la economía global. Antes de la crisis industrial existía una depresión estructural en el sector primario.

En 1925-1930 también se registra depresión estructural en los productos primarios, por tanto, antes de 1929, cuando se produce la crisis global de la economía; alcanzando a las actividades industriales; pero la transmisión siguió entonces un mecanismo distinto; la caída relativa de precios de bienes primarios alcanzó a las industrias por la vía de la demanda, disminuyendo el comercio mundial de productos industriales, lo cual engendró una caída del índice internacional de precios. En este período la subida de la RI de productos primarios tuvo lugar durante el proceso de la depresión económica de la década de 1930, probablemente porque surgió por entonces la escasez de bienes primarios, por descenso de stocks (así se aprecia en Canadá, Estados Unidos y Argentina), que presionaría sobre el precio, y también por decisiones de política agrícola, ostensibles en el caso de Estados Unidos.

Tanto en la crisis de 1929 como en la de 1973, observamos la presencia de una depresión agrícola estructural con anterioridad a la crisis internacional; ello nos lo corroboran los datos, pero la explicación de la causalidad en una y otra es diferente; entiendo que, en 1929-1933, la caída de los precios relativos del sector primario actuó depresivamente sobre la economía global por el lado de la demanda; y, durante los años de 1971-1973, la deflación estructural del sector primario ocasionó, por vía de oferta, un aumento de los costes y de los precios industriales que llevó al estancamiento económico con inflación monetaria. 


\section{FUENTES CUANTITATIVAS}

Annual Statement of the Trade of the United Kingdom, Her Majesty's Stationery.

Canada Year Book, Ministry of Industry, Trade and Customs.

CEPAL: Anuario Estadístico de América Latina, Naciones Unidas, Nueva York.

FAO: World Grain Trade Statistics, Roma.

- Trade Yearbook, United Nations, Roma.

- Production Year Book, United Nations, Roma.

Historical Statistics of Canada (1965), Cambridge University Press, Toronto.

International Monetary Fund (1983): Balance of Payments Statistics.

International Year Book of Agricultural Statistics, Roma.

Mitchell, B. R., y Deane, Ph. (1962): Abstract of British Historical Statistics, Cambridge University Press.

Mrtchell, B. R., y Jones (1971): Second Abstract of British Historical Statistics, Cambridge University Press.

OCDE (1983): Main Economic Indicators, Department of Economics and Statistics.

UNITEd Nations: Statistical Yearbook, Nueva York.

- (1981): Supplement Handbook of International Trade and Development Statistics. Supplement United Nations, Nueva York.

- Yearbook of International Trade Statistics, Nueva York.

- National Accounts Statistics, Nueva York.

U. S. Department of Commerce (Bureau of the Census): Historical Statistics of the United States, Colonial Times to 1970, I y II, Washington.

- Historical Abstract of the United States, Washington.

- (Bureau of Foreign and Domestic Commerce): Foreign Commerce and Navigation of the United States, Washington.

Year Book Australia, Australian Bureau of Statistics, Camberra.

\section{BIBLIOGRAFIA}

Balassa, B. (1982): Development Strategies in Semi-industrial Economies.

Coldman, D. (1972): The United Kingdom Cereal Market. An Econometric Investigation into the effects of pricing policies, Manchester University Press.

Copland, D. B. (1934): Australia in the World Crisis, 1929-33, Cambridge University Press, Nueva York.

- (1941): The Australian Economy.

Currie, L. (1980): «Causes of the Recession», en History of Political Economy, 12 (noviembre), 3.

Dfaz Alejandro, C. F. (1973): Ensayos sobre la bistoria económica argentina, Amorrortu Editores, Buenos Aires.

- (1985): «Los primeros años de la década de 1980 en Latinoamérica: cotra vez los años treinta?», en REVISTA DE Historia Económica, año III, núm. 2 (primaveraverano), $205-207$.

Farnsworth, H., y Timoshenko, V. P. (1945): World Grain Review and Outlook, Food Research Institute, Stanford University.

Fraile, P., y Hernandez Andreu, J. (1986): «The Twentieth Century's Two Big Crises: Origins and Similarities*, en The Ninth International Economic History Congress, 5 Section (The Impact of the Depression of the 1930 s and its Relevance for the Contemporary World), Budapest, 355-370.

Hernd́ndez ANDreu, J. (1980): Depresión económica en España, 1925-1934, Ed. Instituto de Estudios Fiscales, Madrid. 
Hevesy, P. (1940): World Wheat Planning and Economic Planning in General, Oxford University Press, Londres, Nueva York y Toronto.

HILGERDT, F. (1945): Industrialization and Foreign Trade, League of Nations, Nueva York. KeMP, T. (1981): Modelos bistóricos de industrialización, Ed. Fontanella, Barcelona.

Kindleberger, Ch. (1965): Economic Development, McGraw-Hill Inc., Nueva York.

- (1968): International Economics, R. D. Irwin Inc., Homewood (Illinois).

- (1973): The World in Depression 1929-1939, University of California Press, Berkeley y Los Angeles.

LAthaM, A. J. H., y NenL, L. (1983): "The International Market in Rice and Wheat 1868-1914\%, en The Economic History Review, second series, XXXVI, 2 (mayo), 260-279.

Lewis, W. A. (1952): *World Production, Prices and Trade, 1870-1960», en The Manchester School of Economic and Social Studies, XX, 2 (mayo).

LIT $\mathrm{w}$ wICK, N. H. (1967): Economic Growth in Canada. A Quantitative Analysis, University Toronto Press.

McCalla, A., y Josling, T. (1981): Imperfect Markets in Agricultural Trade, Allanheld, Osmun \& Co. Publishers Inc., New Jersey.

McGibBoN, D. A. (1952): The Canadian Grain Trade 1931-1951, University of Toronto Press.

Malenbaum, W. (1953): The World Wheat Economy 1885-1939, Harvard University Press.

Norton, W. E., y McDonald, R. (1983): «The Declive in Australia's Economic Performance in the 1970. An Analysis of Annual Data», en Australian Economic Papers, 22, 40 (junio), 1-29.

Platt, D. C. M., y Di Tella, G. (1985): Argentina, Australia and Canada, Oxford.

Rosrow, W. W. (1978): The World Economy. History and Prospect, University of Texas Press, Austin. Edición en castellano: Economia Mundial, Ed. Reverte, Barcelona, 1983.

Talbot, R. B. (1976): The World Food Problem and U. S. Food Politics and Policies: 1972-1976. A Readings Book Iowa State University Press, Ames (Iowa).

- (1978): The World Food Problem and U. S. Food Politics and Policies. A Readings Book, Iowa State University Press, Ames (Iowa).

Temin, P. (1976): Did Monetary Forces Cause The Great Depression?, W. W. Norton \& Company Inc., Nueva York.

Tim os Henko, V. (1953): World Agriculture and the Depression, University of Michigan. 